\title{
Seismo-ionospheric anomalies in ionospheric TEC and plasma density before the 17 July 2006 M7.7 south of Java earthquake
}

\author{
Dan Tao ${ }^{1}$, Jinbin Cao ${ }^{1}$, Roberto Battiston ${ }^{2}$, Liuyuan $\mathrm{Li}^{1}$, Yuduan $\mathrm{Ma}^{1}$, Wenlong Liu ${ }^{1}$, Zeren Zhima ${ }^{1}$, Lanwei Wang ${ }^{3}$, \\ and Malcolm Wray Dunlop ${ }^{1}$ \\ ${ }^{1}$ Space Science Institute, School of Space and Environment, Beihang University, Beijing, China \\ ${ }^{2}$ Dipartimento di Fisica, Università di Trento, Trento, Italy \\ ${ }^{3}$ Institute of Crustal and Dynamics, China Earthquake Administration, Beijing, China \\ Correspondence to: Jinbin Cao (jbcao@buaa.edu.cn)
}

Received: 18 February 2017 - Revised: 6 April 2017 - Accepted: 7 April 2017 - Published: 25 April 2017

\begin{abstract}
In this paper, we report significant evidence for preseismic ionospheric anomalies in total electron content (TEC) of the global ionosphere map (GIM) and plasma density appearing on day 2 before the 17 July 2006 M7.7 south of Java earthquake. After distinguishing other anomalies related to the geomagnetic activities, we found a temporal precursor around the epicenter on day 2 before the earthquake (15 July 2006), which agrees well with the spatial variations in latitude-longitude-time (LLT) maps. Meanwhile, the sequences of latitude-time-TEC (LTT) plots reveal that the TECs on epicenter side anomalously decrease and lead to an anomalous "asymmetric" structure with respect to the magnetic equator in the daytime from day 2 before the earthquake. This anomalous "asymmetric" structure disappears after the earthquake. To further confirm these anomalies, we studied the plasma data from DEMETER satellite in the earthquake preparation zone (2046.4 $\mathrm{km}$ in radius) during the period from day 45 before to day 10 after the earthquake, and also found that the densities of both electron and total ion in the daytime significantly increase on day 2 before the earthquake. Very interestingly, $\mathrm{O}^{+}$density increases significantly and $\mathrm{H}^{+}$density decreases, while $\mathrm{He}^{+}$remains relatively stable. These results indicate that there exists a distinct preseismic signal (preseismic ionospheric anomaly) over the epicenter.
\end{abstract}

Keywords. Ionosphere (ionospheric disturbances)

\section{Introduction}

In recent years, seismo-ionospheric anomalies occurring before large earthquakes have been widely investigated. The total electron content (TEC) derived from measurements of local ground-based GPS receivers is used first by Liu et al. (2001) to study the variations in ionospheric electron density before the 1999 M7.6 Chi-Chi earthquake and they found that the TEC decreases in the afternoon period on day 1,3 and 4 before this earthquake. This preearthquake precursor is further confirmed by Liu et al. (2004) through a statistical analysis of global ionosphere map (GIM) TEC during the $20 M \geq 6.0$ earthquakes in Taiwan from September 1999 to December 2002. After that, more similar studies were done by using the GIM to study TEC anomalies before large earthquakes, and many striking results have been found. For example, the statistical result of Liu et al. (2009) indicates that the GIM TEC above the epicenter often pronouncedly decreased on days 3-5 before $17 M \geq 6.3$ earthquakes during the 10-year period from 1 May 1998 to 30 April 2008. Liu et al. (2010) reported seismo-ionospheric precursors of anomalous decreases in TEC, which appear 5 days prior to the 26 December 2004 M9.3 Sumatra-Andaman earthquake. For the 2008 M8.0 Wenchuan earthquake, remarkable precursors are also observed locally around both the epicenter and its conjugate point (Jhuang et al., 2010; Kakinami et al., 2010; Liu et al., 2009; Yan et al., 2012; Zhao et al., 2008). It is also found that the TEC over the epicenter significantly enhances on day 1 before the 12 January $2010 M 7$ Haiti earthquake. The TECs of the two midlatitude dense strips on $35^{\circ} \mathrm{N} / 60^{\circ} \mathrm{S}$ and those 
of the epicenter/conjugate point reach their maximum values on day 1 before the earthquake, while the northern crest of equatorial ionization anomaly (EIA) moves poleward (Liu et al., 2011).

Meanwhile, many studies of earthquake ionospheric precursors have been performed using the data from orbiting satellites. The French DEMETER (Detection of ElectroMagnetic Emissions Transmitted from Earthquake Regions) satellite has highly sensitive measurements over seismically active and quiet regions, and provides another efficient and supplementary way to study earthquake-related ionospheric variations. Using the DEMETER data, Zhang et al. (2009a, b) reported some ionospheric anomalies possibly related to the 12 May 2008 M8.0 Wenchuan earthquake, such as the smallest value in $\mathrm{O}^{+}$density and the ion temperature variations on 9 May above the epicenter, and the ionosphere VLF electric field anomalies. The statistical results of Akhoondzadeh et al. (2010) indicate that the positive and negative anomalies in both of DEMETER and TEC data during days $1-5$ before all studied earthquakes during quiet geomagnetic conditions are highly regarded as seismo-ionospheric precursors. Zhima et al. (2012a, b) show that possible ionospheric electromagnetic perturbations occurred 4 days before the earthquake in the ELF/VLF frequency range. Yan et al. (2014) show that among 37 earthquakes under study, positive electron density anomalies occur before earthquakes, mostly within days $1-6$ before the shocks. A statistical analysis of the box-and-whisker method also shows that the nighttime $\mathrm{Ne}$ and $\mathrm{Ni}$ (daytime $\mathrm{Ti}$ ) over the epicenter significantly decrease (increase) days $1-6$ before the 2008 M8.0 Wenchuan earthquake (Liu et al., 2015).

There are several simultaneous observations of seismoionospheric anomalies in the GPS TEC and in situ electron density from orbiting satellites (Karia et al., 2012; Ho et al., 2013; Liu et al., 2016), but there are very few cross-validation analyses between TEC and plasma characteristics anomalies at almost the same time before an impending earthquake. In the present paper, we, using the GPS TEC and DEMETER plasma data, studied the ionospheric variations over the epicenter of the 17 July 2006 M7.7 south of Java earthquake. The results indicate that seismo-ionospheric anomalies in the GPS TEC and in situ plasma density occur at almost the same time over the epicenter.

\section{Data}

\subsection{Earthquake data}

The magnitude $M 7.7$ earthquake occurred in the south of Java $\left(9.28^{\circ} \mathrm{S}, 107.42^{\circ} \mathrm{E}\right.$ ) at $20 \mathrm{~km}$ depth at $08: 19 \mathrm{UT}$ (universal time) on 17 July 2006. Figure $1 \mathrm{~b}$ displays the earthquake location and its preparation zone with a radius $\rho=$ $2046.4 \mathrm{~km}$, which is estimated by using the Dobrovolsky formula $\rho=10^{0.43 \cdot M}$ (Dobrovolsky et al., 1979). All earth- quake data are obtained from the National Earthquake Information Center (NEIC) ComCat database of the US Geological Survey. There are 76 earthquakes $(M \geq 5.0)$ around the south of Java main shock from 2 June to 20 July 2006, and almost all of them are aftershocks (Fig. 1c). This provides a favorable condition for the precursor analysis of the earthquake in the south of Java on 17 July 2006.

\subsection{GPS satellite data}

The GPS satellites transmit two L-band signals at the frequencies of 1575.42 and $1227.60 \mathrm{MHz}$ and offer an effective method for monitoring the ionosphere. The TEC is a measure of the total number of electrons that would be contained in a cylinder that extends up vertically above a given point on the Earth all the way through the ionosphere. The network of GPS receivers can be used to simultaneously and continuously monitor the TEC. The GIM TEC data are provided by the Center for Orbit Determination in Europe $(\mathrm{CODE})$ and the GIM maps are constructed into $2.5^{\circ} \times 5^{\circ}$ (latitude $\times$ longitude) grid covering $\pm 87.5^{\circ} \mathrm{N}$ latitude and $\pm 180^{\circ} \mathrm{E}$ longitude ranges with $2 \mathrm{~h}$ time resolution (Schaer, 1999). In this paper, the TEC data based on the date and geographic location of south of Java earthquake from day 75 before to day 10 after (3 May to 27 July 2006) the main shock were processed.

\subsection{DEMETER satellite data}

The French micro-satellite DEMETER was devoted to the investigation of the ionospheric disturbances due to seismic activity. DEMETER was launched in June 2004 on a quasi-Sun-synchronous circular orbit with an inclination of $\sim 98.23^{\circ}$ and an altitude of $\sim 710 \mathrm{~km}$ (Parrot et al., 2006). Due to the specific orbit, plasma measurements are done at two different local times, 10:30 and 22:30. DEMETER has two science operation modes: (i) a survey mode to collect data all around the Earth at invariant latitudes less than $\sim 65^{\circ}$ and (ii) a burst mode to record data above the seismic regions.

In this study, we have used the electron density and temperature data from ISL (Langmuir probe) (Lebreton et al., 2006) and ion $\left(\mathrm{H}^{+}, \mathrm{He}^{+}\right.$and $\left.\mathrm{O}^{+}\right)$density and temperature data from IAP (plasma analyzer) (Berthelier et al., 2006) in both survey and burst modes. Archived data are available by half-orbits through the DEMETER data server (https: //sipad-cdpp.cnes.fr/). The data recorded by ISL and IAP aboard DEMETER over the preparation zone of south of Java earthquake (Fig. 1b) from day 45 before to day 10 after the earthquake were selected. 

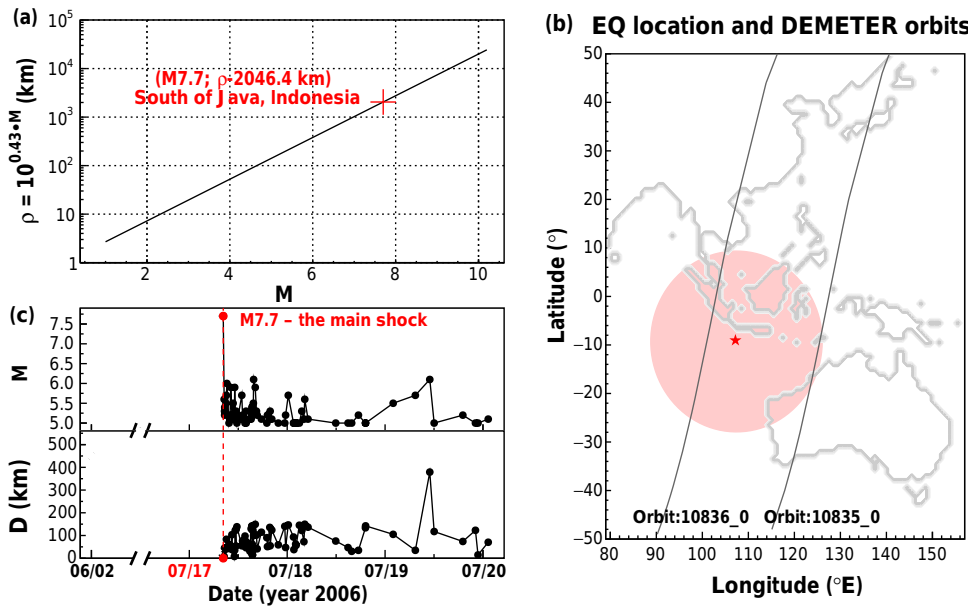

Figure 1. The information of the main shock $\left(M 7.7,17\right.$ July 2006, south of Java). (a) The radius $\left(\rho=10^{0.43 \cdot M}\right)$ of earthquake preparation zone. (b) The location of the main shock (the red star) and its preparation zone (the light-red circle). The two black curves show two downward half-orbits (10835_0 and 10836_0) of DEMETER satellite in the daytime on day 2 before the main shock (15 July 2006). (c) The $M \geq 5.0$ earthquakes occurred around the main shock from 2 June to 20 July 2006: (top) the magnitudes and (bottom) the distances from the main shock, where the two red dots represent the main shock.

\section{Applied methods and observations}

\subsection{TEC anomalies}

As in Liu et al. (2004), the median and the interquartile range of data are utilized to construct their upper and lower bound in order to separate seismic anomalies from the background of normal variations. The upper and lower bounds of the mentioned range can be calculated using Eqs. (1)-(4) (Akhoondzadeh et al., 2010):

$x_{\mathrm{UB}}=M_{30}+k \cdot \mathrm{IQR}$,

$x_{\mathrm{LB}}=M_{30}-k \cdot \mathrm{IQR}$,

$D_{x}=\left(x-M_{30}\right) / \mathrm{IQR},\left(x_{\mathrm{LB}}<x<x_{\mathrm{UB}}\right)$

$p= \pm\left[\left(D_{x}-k\right) / k\right] \cdot 100 \%$,

where $x, x_{\mathrm{UB}}, x_{\mathrm{LB}}, M_{30}$, IQR, $D_{x}, k$ and $p$ are the TEC value, upper bound, lower bound, 30-day running median value, interquartile range, differential of TEC, threshold value of the anomaly, and percentage of TEC change from the undisturbed state, respectively. If the absolute value of $D_{x}$ is larger than the $k$ value $\left(\left|D_{x}\right|>k\right)$, the behavior of the relevant TEC value will be regarded as anomalous. Considering the magnitude of the main shock, here we set value $k=2.0$.

We first examine the variations in geomagnetic Dst and $\mathrm{Kp}$ index and solar flux F10.7 index during the period from 2 June to 27 July 2006 , i.e., day 45 before to day 10 after the 17 July 2006 M7.7 south of Java earthquake. As seen from Fig. 2, geomagnetic and solar activities are relatively weak during this period. Nevertheless, we still adopt a stringent condition (Dst $>-30 \mathrm{nT}, \mathrm{Kp}<3$ and F10.7 $<100 \mathrm{sfu}$ ) to separate preseismic ionospheric phenomena from the ionospheric disturbances due to the magnetospheric and solar ac- tivities. We compute the TEC around the epicenter by using a linear interpolation of four data points nearest the epicenter $\left(9.28^{\circ} \mathrm{S}, 107.42^{\circ} \mathrm{E}\right)$. Since the resolutions of the GIM TEC are $2.5^{\circ}$ in latitude and $5^{\circ}$ in longitude, we take the data point centers within the ranges of $7.5-10^{\circ} \mathrm{S}$ and 105 $110^{\circ}$ E. Figure $2 \mathrm{~d}$ illustrates the DTEC values from 2 June to 27 July 2006 close to the epicenter, which are computed according to Eq. (3).

In our study, anomalous TEC time is searched only within the interval during which $|\mathrm{DTEC}|>2.0$, Dst $>-30 \mathrm{nT}$, $\mathrm{Kp}<3$ and $\mathrm{F} 10.7<100$ sfu, and the TEC anomaly days are the days during which the total anomalous TEC time exceed $6 \mathrm{~h}$ within the range of 00:00-24:00 LT (local time). In Fig. 2d, the TEC anomaly is a function of time (LT-UT) and number of days relative to the main shock onset (marked with a red star). As shown in Fig. 2d, the day 2 before the earthquake is the TEC anomaly day (15 July 2006). There are strong enhancement of TEC anomaly during the periods of 02:00-04:00 UT (09:00-11:00 LT, +9.35\% increases) and 04:00-06:00 UT (11:00-13:00 LT, +9.70\% increases), and an anomalous reduction during 12:00-14:00 UT (19:0021:00 LT, $-1.67 \%$ decreases). This is consistent with the previous results that the preseismic ionospheric anomalies can be positive as well as negative (Akhoondzadeh et al., 2010; Pulinets and Davidenko, 2014; Pulinets et al., 2003, 2015).

\subsection{Spatial anomalies on latitude-longitude-time (LLT) maps}

For the abovementioned three anomalous periods, we conduct a spatial analysis to check if the GIM TECs simultaneously perturb in the earthquake region. Each GIM map con- 

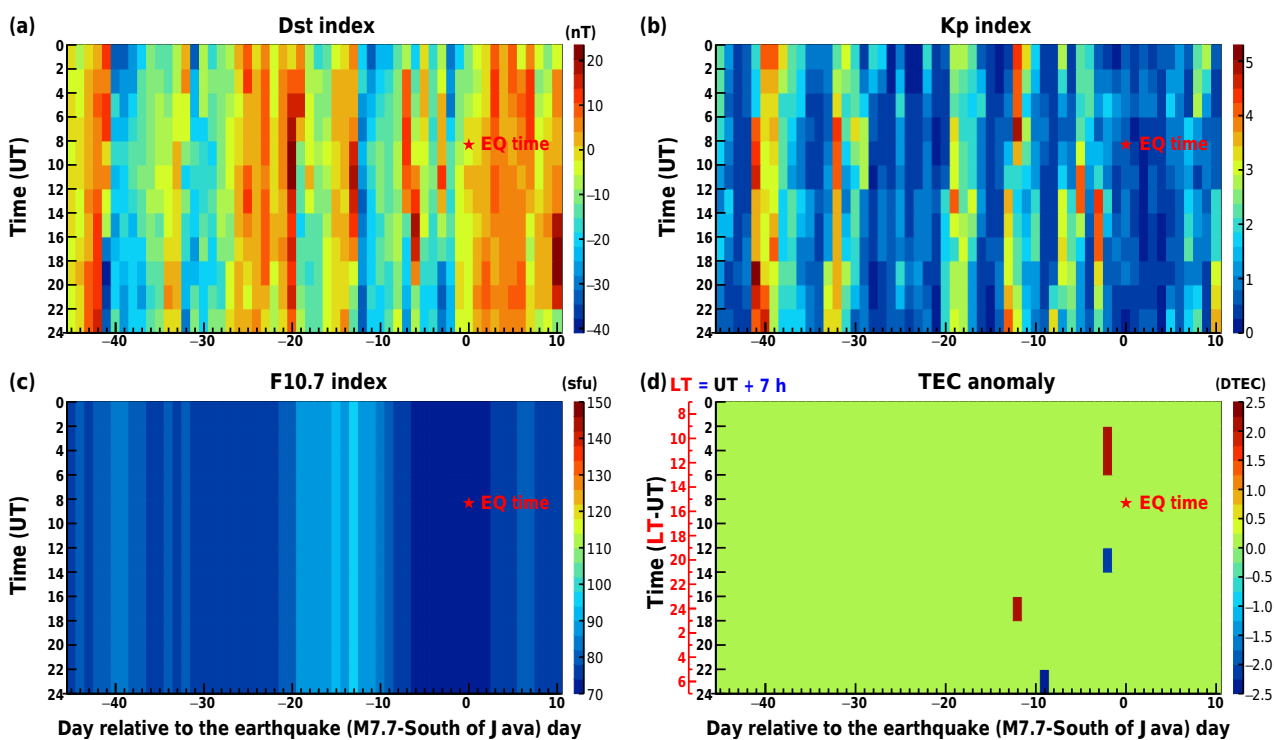

Day relative to the earthquake (M7.7-South of J ava) day

Figure 2. TEC anomaly analysis for the south of Java earthquake (17 July 2006) from 2 June to 27 July 2006. The earthquake time is represented by a red star. The $x$ axis represents the day relative to the earthquake day. The $y$ axis represents the UT (LT $=\mathrm{UT}+7 \mathrm{~h})$. (a) Dst geomagnetic index. (b) Kp geomagnetic index. (c) Solar radio flux F10.7 index. (d) TEC anomaly detected under the following conditions: Dst $>-30 \mathrm{nT}, \mathrm{Kp}<3, \mathrm{~F} 10.7<100 \mathrm{sfu}$ and $|\mathrm{DTEC}|>2.0$. Here 1 TECU $=10^{16}$ electrons $^{-2}$.

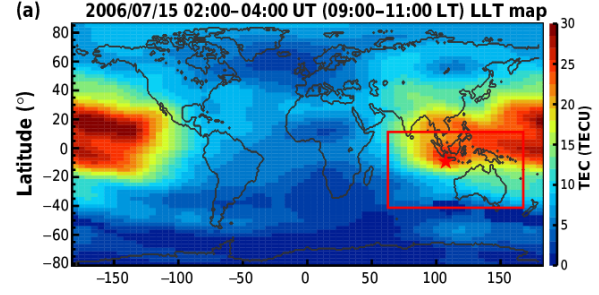

(b) 2006/06/17-07/16 02:00-04:00 UT 30-day median LLT map

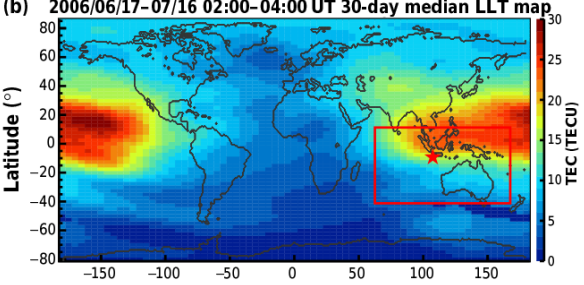

(c) 2006/07/15 02:00-04:00 UT difference LLT (|DTEC|>2.0) map

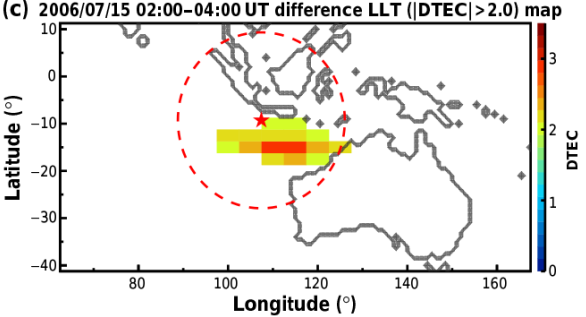

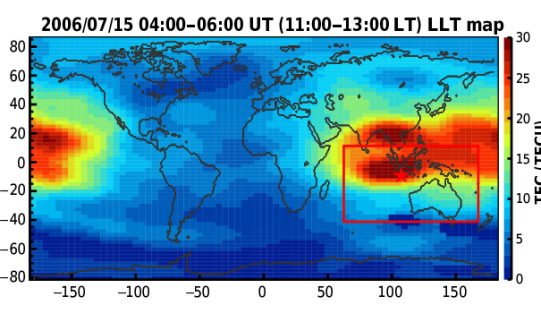
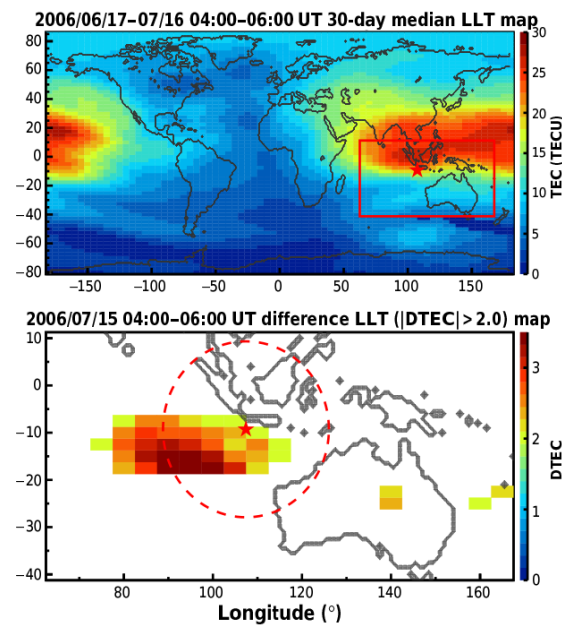
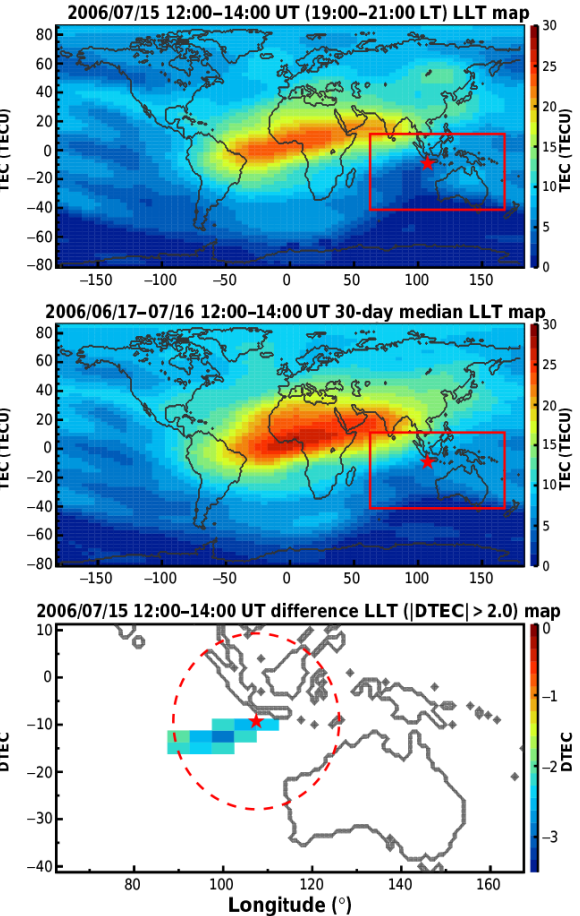

Figure 3. The GIM latitude-longitude-time (LLT) maps observed during the period of 02:00-04:00, 04:00-06:00 and 12:00-14:00 UT on day 2 before the 17 July 2006 M7.7 south of Java earthquake. The GIM LLT maps during the fixed period of 02:00-04:00 UT (left column), 04:00-06:00 UT (middle column) and 12:00-14:00 UT (right column). Panels of row (a) are the observed values on day 2 before the earthquake (15 July 2006), while row (b) shows the median values of the period of days 1-30 before (17 June to 16 July 2006) the earthquake. The red squares in rows $(\mathbf{a}, \mathbf{b})$ indicate the regions of interest around the earthquake, in range of $41.25^{\circ} \mathrm{S}-11.25^{\circ} \mathrm{N}$ latitude and $62.5-167.5^{\circ} \mathrm{E}$ longitude. Panels of row (c) denote the extreme differences ( $\mid$ DTEC $\mid>2.0$ ) of the 30-day period that appeared on 15 July 2006 . The color denotes the difference value of the TEC observed on 15 July 2006 from the relevant median value. The red dashed circles with the radius $\rho=2046.4 \mathrm{~km}$ represent the earthquake preparation area of the lithosphere. 


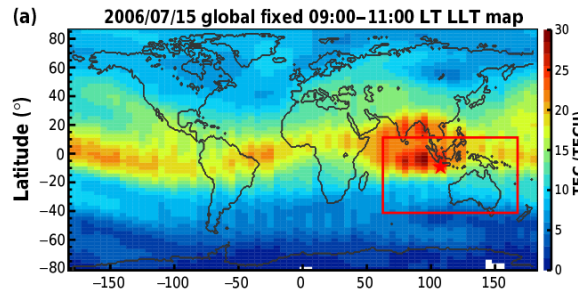

(b) 2006/06/17-07/16 09:00-11:00 LT 30-day median LLT map

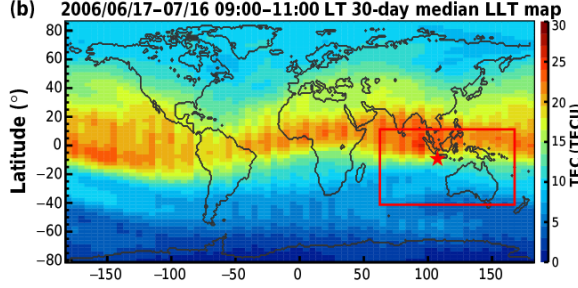

(c) 2006/07/15 09:00-11:00 LT difference LLT (|DTEC|> 2.0) map

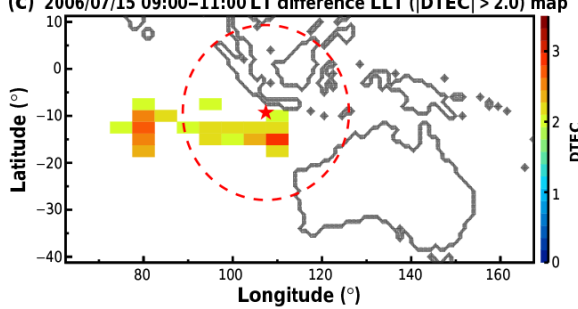

2006/07/15 global fixed 11:00-13:00 LT LLT map

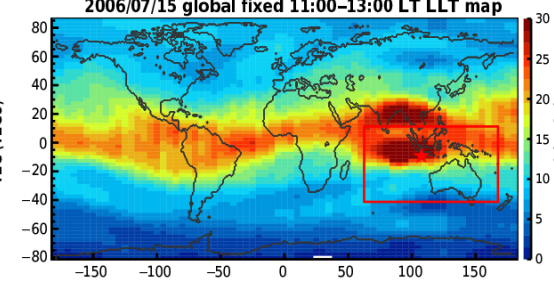

2006/06/17-07/16 11:00-13:00 LT 30-day median LLT map
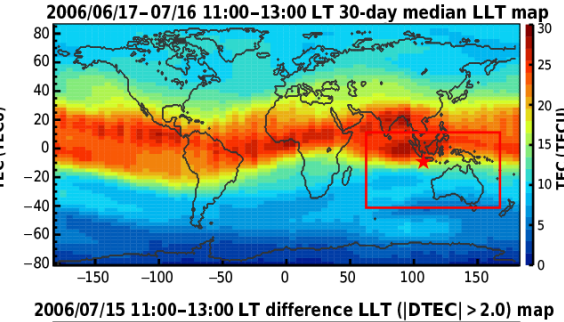

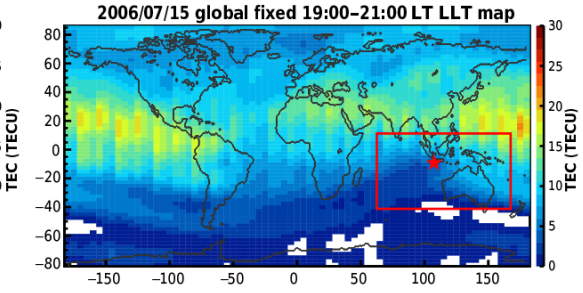

2006/06/17-07/16 19:00-21:00 LT 30-day median LLT map

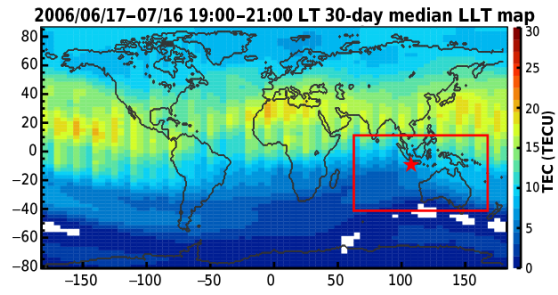

2006/07/15 19:00-21:00 LT difference LLT (|DTEC|> 2.0) map

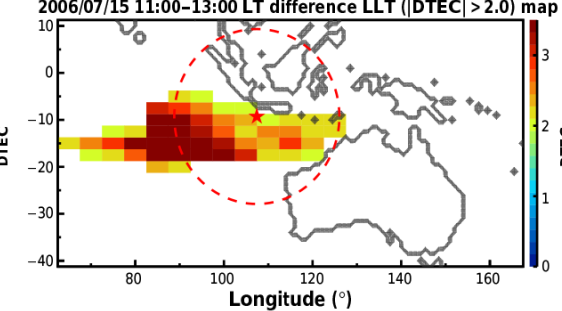

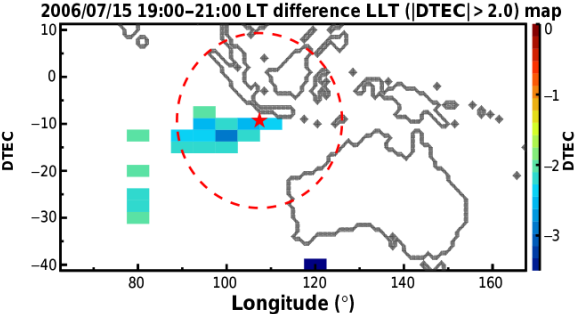

Figure 4. The GIM LLT maps observed during the global fixed period of 09:00-11:00, 11:00-13:00 and 19:00-21:00 LT on day 2 before the 17 July 2006 M7.7 south of Java earthquake. The GIM LLT maps during three global fixed local times: (left column) 09:00-11:00 LT, (middle column) 11:00-13:00 LT and (right column) 19:00-21:00 LT, respectively. Panels of row (a) show the observed values on day 2 before the earthquake (15 July 2006), while those of (b) show the median values of the period of days 1-30 before (17 June to 16 July 2006 ) the earthquake. The red squares in rows $(\mathbf{a}, \mathbf{b})$ indicate the regions of interest around the earthquake, in the range of $41.25^{\circ} \mathrm{S}-11.25^{\circ} \mathrm{N}$ latitude and $62.5-167.5^{\circ}$ E longitude. Panels of row (c) denote the extreme differences ( $\mid$ DTEC $\mid>2.0$ ) of the 30-day period, which appeared on 15 July 2006. The red dashed circles with the radius $\rho=2046.4 \mathrm{~km}$ represent the earthquake preparation area of the lithosphere.

sists of $5040(70 \times 72)$ grid points, and covers $\pm 87.5^{\circ} \mathrm{N}$ latitude and $\pm 180^{\circ} \mathrm{E}$ longitude ranges with spatial resolutions of $2.5^{\circ}$ in latitude and $5^{\circ}$ in longitude, respectively.

Figure 3a shows the GIM TECs LLT map for each anomalous period. We compute the median of the GIM TECs for each grid point in each anomalous period during day 1-30 before the earthquake, i.e., 17 June to 16 July 2006 (Fig. 3b). Figure $3 \mathrm{c}$ shows the extreme differences $(|\mathrm{DTEC}|>2.0$ ) between the observed GIM TEC and the associated 30day median at three anomalous periods that appeared on 15 July 2006, i.e., 02:00-04:00 UT (left), 04:00-06:00 UT (middle) and 12:00-14:00 UT (right). Here, the 30-day median represents the undisturbed background of GIM TECs, while the positive (negative) difference represents the enhancement (reduction) of the GIM TECs.

As shown in Fig. 3c, the ionospheric GIM TECs around the south of Java earthquake epicenter marked by the red dashed circle drastically enhance by $\sim 0.81-42.14 \%$ in the period of 02:00-04:00 UT (09:00-11:00 LT) and $\sim 0.51-$ 94.49\% in the period of 04:00-06:00 UT (11:00-13:00 LT) and decrease by $\sim 4.72-47.44 \%$ in the period of $12: 00$ 14:00 UT (19:00-21:00 LT). The red circle with a radius of $2046.4 \mathrm{~km}$ represents the earthquake preparation zone of the lithosphere. In order to exclude the local time and/or EIA effects, the sequence of GIMs for three corresponding global fixed local times is examined. As shown in Fig. 4, compared with the TEC enhancements or reductions at three different universal times in Fig. 3, the corresponding extreme enhancements or reductions in the GIM TECs at global fixed local times are also mainly located around the forthcoming epicenter and EIA region. Therefore, the spatial anomalies simultaneously and prominently appear in the three anomalous periods on the TEC anomaly day (15 July 2006) around the epicenter of the south of Java earthquake.

\subsection{Asymmetry on latitude-time-TEC (LTT) plots}

We apply another spatial analysis to further confirm the preseismic anomaly related to the south of Java earthquake. We first extract the GIM TEC along the epicenter longitude $107.42^{\circ} \mathrm{E}$ to produce LTT plots of the 12-day period (day 8 before and day 3 after the earthquake) from 9 to 20 July 2006 (Fig. 5), and then compute the TEC around the epicenter longitude $107.42^{\circ} \mathrm{E}$ by using a linear interpolation of two data points from the nearest longitudes ( 105 and $\left.110^{\circ} \mathrm{E}\right)$. 

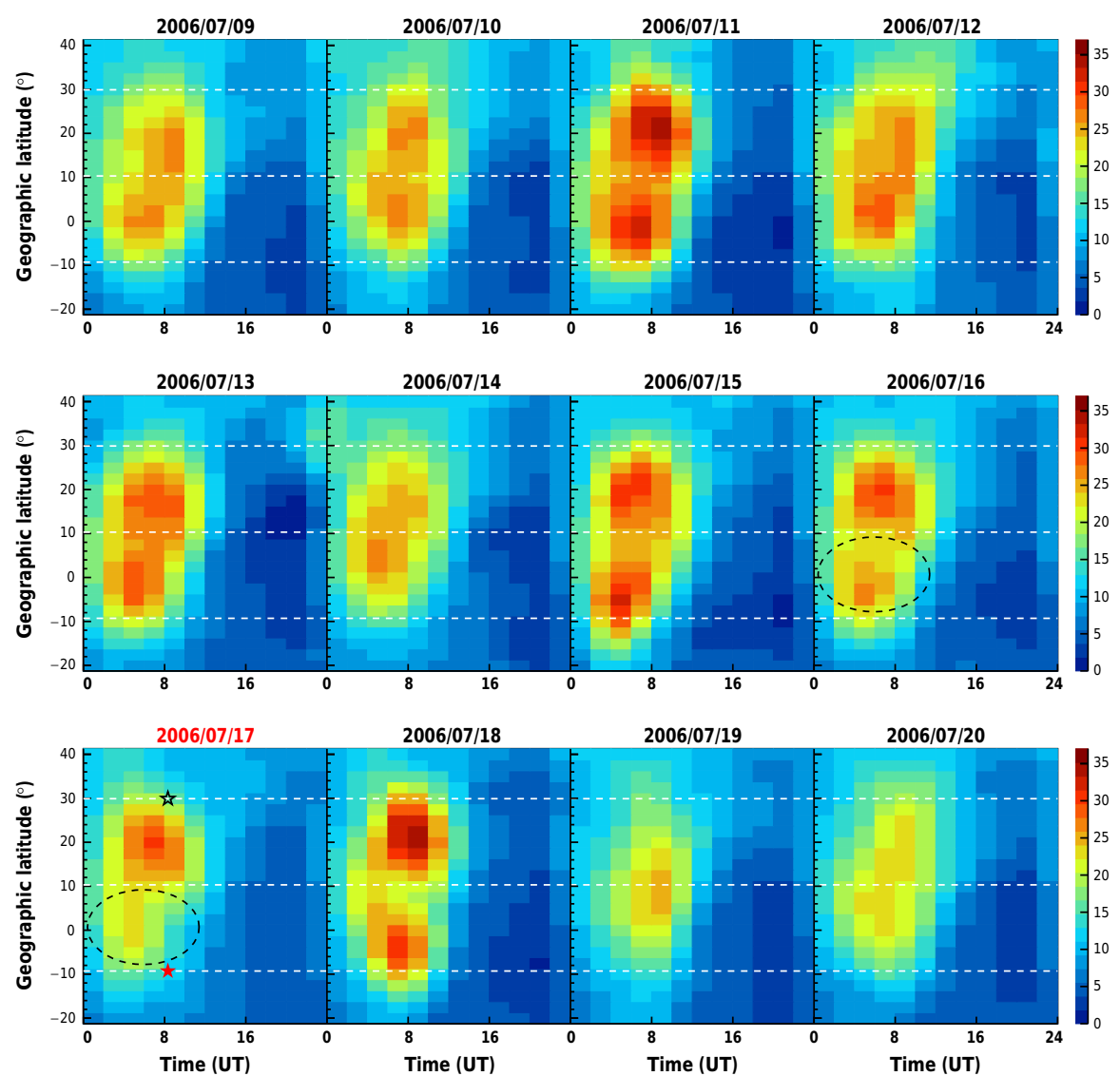

Figure 5. Latitude-time-TEC (LTT) plots along the earthquake longitude (107.42 ${ }^{\circ}$ E) extracted from the GIM during 9-20 July 2006 . The solid and open star symbols are the epicenter and corresponding conjugate point of the south of Java earthquake, respectively. The three dashed white lines from the bottom to top denote magnetic latitudes of the epicenter, magnetic equator, and conjugate point, respectively. The two black dashed ellipses are the regions of anomalous "asymmetry" during the period of 02:00-10:00 UT (09:00-17:00 LT) on 16 and 17 July 2006.

It can be seen from Fig. 5 that the ionospheric GIM TEC between $10^{\circ} \mathrm{S}$ and $10^{\circ} \mathrm{N}$ along the epicenter longitude marked by the black dashed ellipses significantly reduces on 16 and 17 July 2006. As a result, an anomalous "asymmetric" structure is formed between the epicenter-side and corresponding conjugate-side regions with respect to the magnetic equator $\left(\sim 10^{\circ} \mathrm{N}\right)$. In order to quantify this kind of asymmetry, we introduce an asymmetry coefficient $\alpha_{m}$, which is expressed in Eq. (5), to indicate the temporal variation in LTT asymmetry with respect to the magnetic equator.

$\alpha_{m}=\left(x_{\mathrm{N}}-x_{\mathrm{S}}\right) /\left[0.5 \cdot\left(x_{\mathrm{N}}+x_{\mathrm{S}}\right)\right]$,

where $x_{\mathrm{N}}$ and $x_{\mathrm{S}}$ are the symmetric TEC values in the conjugate side (north) and epicenter side (south) of the magnetic equator, respectively.

Figure $6 \mathrm{a}-\mathrm{d}$ illustrate the distribution of asymmetry coefficient $\alpha_{m}$ of LTTs in Fig. 5 in four continuous periods, i.e., 02:00-04:00, 04:00-06:00, 06:00-08:00 and 08:0010:00 UT, which are before or at the time of the earthquake (08:19 UT), during 9-20 July 2006. The asymmetry coeffi- cients $\alpha_{m}$ at four central symmetric latitude pairs $\left(22.5^{\circ} \mathrm{N}-\right.$ $2.5^{\circ} \mathrm{S}, 20.0^{\circ} \mathrm{N}-0.0^{\circ} \mathrm{S}, 17.5-2.5^{\circ} \mathrm{N}$ and $15.0-5.0^{\circ} \mathrm{N}$ ) with respect to the magnetic equator increase simultaneously from the day 2 before the earthquake (15 July 2006) and reach the peaks on the earthquake day and then return to the normal levels gradually. As shown in Fig. 6, the "asymmetric" structure is the most evident on the earthquake day, and the corresponding asymmetry coefficients $\alpha_{m}$ reach their peaks and increase by $104.62,398.41,672.62$ and $177.75 \%$ from their average levels, respectively. The anomalous "asymmetric" structure occurring before the south of Java earthquake is distinctive and worthy of further study.

\subsection{Plasma variations}

In this study, we have analyzed GIM TEC anomalies extracted from GPS satellites during day 45 before to day 10 after the event over the earthquake epicenter and its preparation zone. In order to confirm observed TEC anomalies, a 


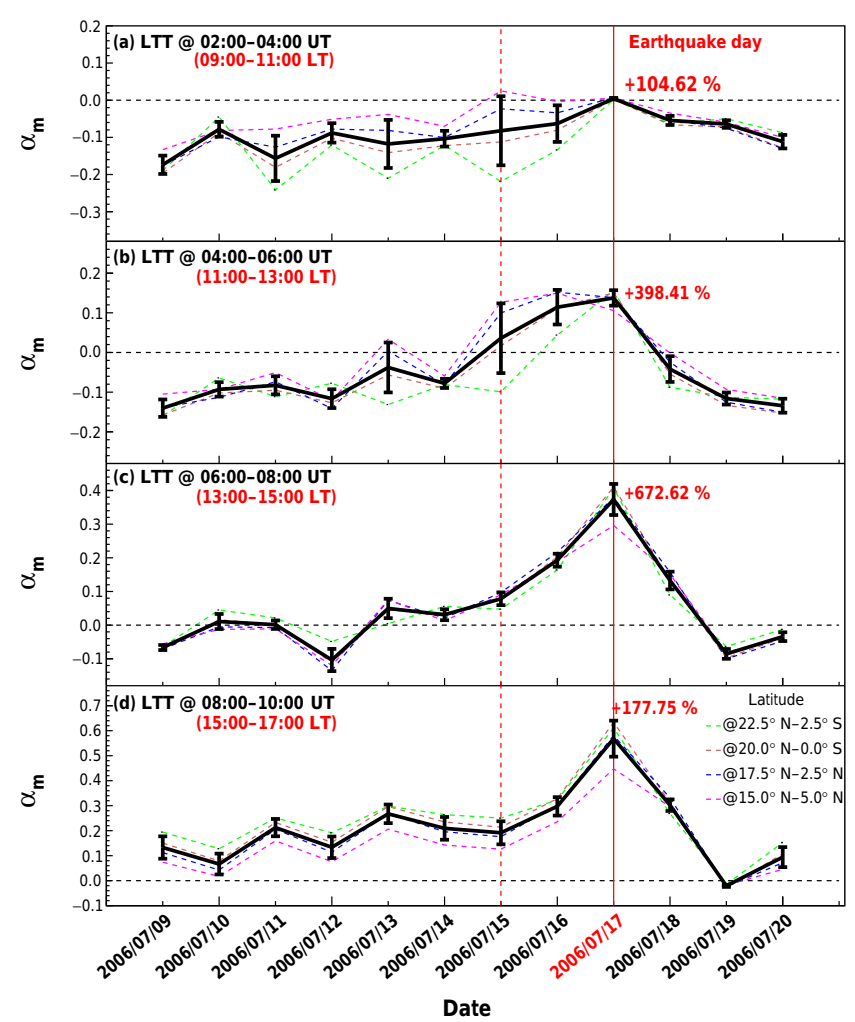

Figure 6. The asymmetry of LTT plots. (a-d) The temporal distribution of asymmetry coefficient $\alpha_{m}$ of LTT plots in Fig. 5 during four continuous time periods, i.e., 02:00-04:00, 04:00-06:00 UT, 06:00-08:00 and 08:00-10:00 UT, from 9 to 20 July 2006. The green, brown, blue and magenta dashed lines represent the distribution of $\alpha_{m}$ of LTT plots at four different symmetric latitude pairs with respect to the magnetic equator, i.e., $22.5^{\circ} \mathrm{N}-2.5^{\circ} \mathrm{S}, 20.0^{\circ} \mathrm{N}-$ $0.0^{\circ} \mathrm{S}, 17.5-2.5^{\circ} \mathrm{N}$ and $15.0-5.0^{\circ} \mathrm{N}$, and the black solid line represents the mean value of that of four different symmetric latitude pairs with respect to the magnetic equator. The earthquake day and day 2 before the earthquake are represented by red vertical solid and dashed lines, respectively.

cross-validation analysis is conducted by using the DEMETER data.

In a similar way to that described in Sect. 3.1, we use the data recorded by ISL and IAP instruments on DEMETER to study the ionospheric parameters above the preparation zone (radius $\rho=2046.4 \mathrm{~km}$ ) during day 45 before (2 June 2006) to day 10 after (27 July 2006) the south of Java earthquake. As the undisturbed reference background, we take the median value $\left(M_{56}\right)$, the upper and lower bounds $\left(M_{56} \pm 2.0 \cdot \mathrm{IQR}\right)$ of each ionospheric parameter during the 56 days.

Figure 7 illustrates variations in different ionospheric parameters above the south of Java earthquake preparation zone in the daytime from 2 June to 27 July 2006. Since the DEMETER satellite sometimes does not pass over the earthquake preparation zone in the daytime, there are several time gaps.
As shown in Fig. 7a and b, both electron and total ion densities increase significantly and reach their maximum values of the study period (exceeding the upper bound by +19.52 and $+13.80 \%$, respectively) on day 2 before the earthquake (15 July 2006). The main component $\mathrm{O}^{+}$density increases by the order of $13.94 \%$ (Fig. 7f) while $\mathrm{H}^{+}$density simultaneously reaches its minimum value (a $11.72 \%$ decrease, Fig. 7e) on 15 July 2006. However, as shown in Fig. 7g, $\mathrm{He}^{+}$ density is relatively stable. Furthermore, the ion temperature reduces oppositely by $1.59 \%$ on 15 July 2006 , on day 2 before the earthquake. The electron temperature also decreases and reaches the minimum value in the daytime on the same day. However, it does not drop below the lower bound.

Also, it should be noted that the plasma parameters reach the extremum values on day 2 before the earthquake (15 July 2006), and in the daytime at about 10:30 LT (03:30 UT, Fig. 7h), when satellite is above the earthquake preparation zone in two downward half-orbits (10835_0 and 10836_0, Fig. 1b). Meanwhile, the DEMETER satellite also passed through the earthquake preparation zone during the nighttime at about 22:30 LT, but we do not see any similar variation before the occurrence of earthquake. This is also consistent with the fact that the GIM TEC enhancements are observed at the same daytime period, i.e., 09:00-13:00 LT (02:00-06:00 UT).

\section{Discussion and conclusion}

The simultaneous anomalies of GIM TEC derived from GPS data and plasma parameters recorded by DEMETER clearly show the preseismic disturbed signals on day 2 prior to the south of Java earthquake over the preparation zone of the impending earthquake. The Dst, Kp and F10.7 indexes are rather small around the earthquake time, which suggests that the anomalies around the epicenter are not caused by the geomagnetic or solar activities within that period. Furthermore, the rare preseismic quiescence (see Fig. 1c) provides a favorable environment for earthquake precursor analysis.

The LLT maps in Fig. 3 show that the anomalies synchronously appear in the earthquake preparation zone in the three universal/local periods, i.e., 02:00-04:00 UT (09:0011:00 LT), 04:00-06:00 UT (11:00-13:00 LT) and 12:0014:00 UT (19:00-21:00 LT) on 15 July 2006, day 2 before the earthquake. Taking into account the local time and/or EIA effects, the geographic region and the signs of anomalies agree very well with those of the same three TEC anomalies (Fig. 2d) on that day. In other words, the TEC anomalies can be the positive enhancements (increase $\sim 0.81-42.14 \%$ in the period of 02:00-04:00 UT and $\sim 0.51-94.49 \%$ in the period of 04:00-06:00 UT) as well as the negative reductions (decrease $\sim 4.72-47.44 \%$ in the evening period of 12:00-14:00 UT). This feature also coincides with the previous results that TEC over the forthcoming epicenter region tends to significantly increase or decrease several 

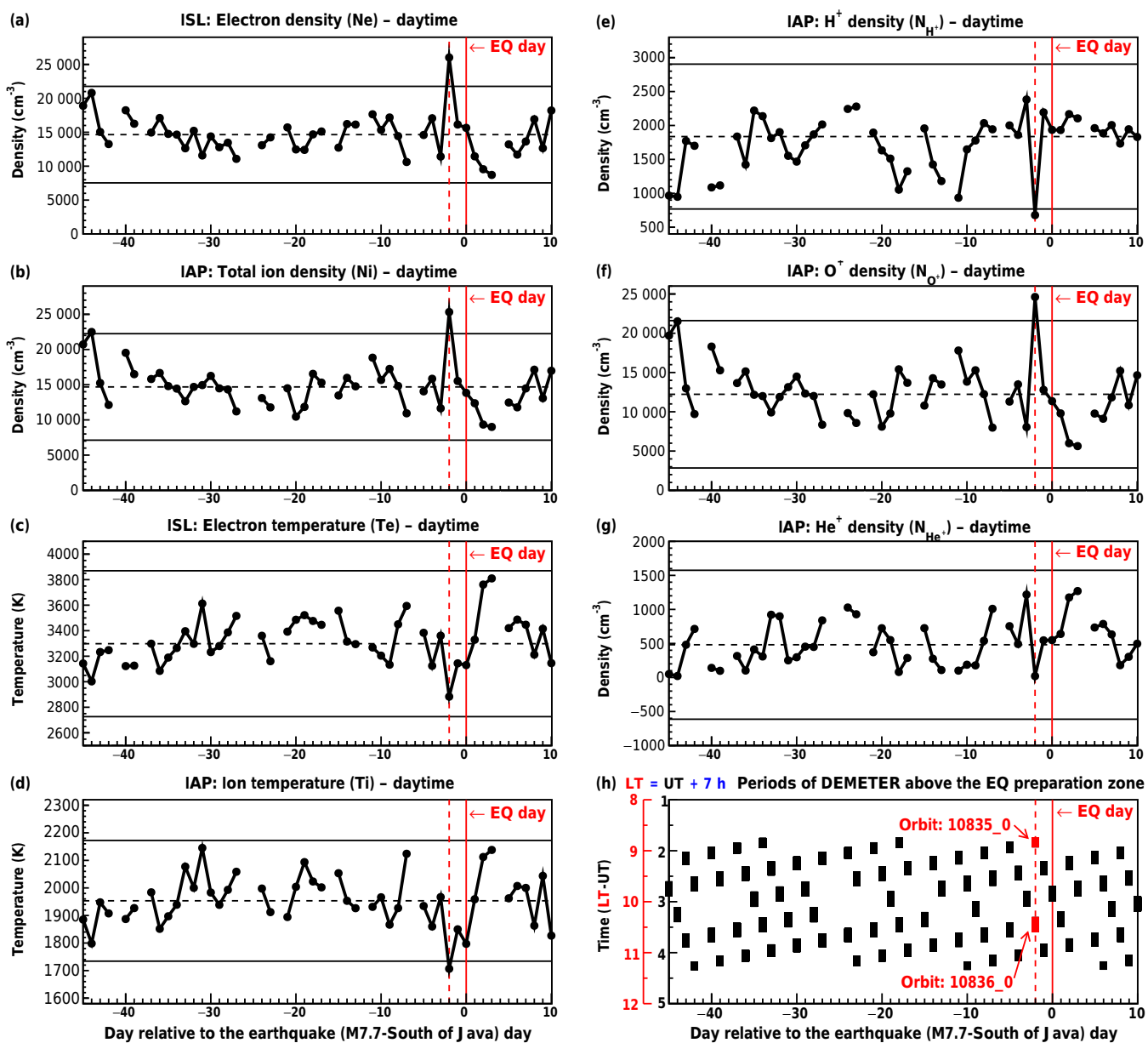

Figure 7. Plasma parameter anomalies above the earthquake preparation zone from 2 June to 27 July 2006. (a) Electron density and (c) electron temperature derived from the measurements of the ISL in the daytime. (b) Total ion density and (d) ion temperature, (e) $\mathrm{H}^{+}$, (f) $\mathrm{O}^{+}$ and $(\mathbf{g}) \mathrm{He}^{+}$density derived from the measurements of IAP in the daytime. Since the DEMETER satellite sometimes did not pass over the earthquake preparation zone in the daytime, there are some time gaps. The black dashed lines indicate the median value $\left(M_{56}\right)$ and the two black solid lines indicate the upper and lower bounds $\left(M_{56} \pm 2.0 \cdot \mathrm{IQR}\right)$. (h) The periods during which DEMETER satellite passed over the earthquake preparation zone in the daytime ( 09:00-10:30 LT). The $x$ axis represents the day relative to the earthquake day. The earthquake day and day 2 before the earthquake are represented by red vertical solid and dashed lines, respectively.

days before the earthquake occurrence (Akhoondzadeh et al., 2010; Ho et al., 2013; Liu et al., 2004, 2011). It should be mentioned that the spatial TEC anomalies are exactly observed during the abovementioned three periods around the epicenter in the global LLT maps, which allow us to exclude the possible induced effects from the weak geomagnetic storm (Dst $=\sim-30 \mathrm{nT}$, from $\sim 18: 00$ UT 14 July to $\sim$ 06:00 UT 15 July) (Fig. 2a). Since another two observed TEC anomalies only last for $2 \mathrm{~h}$ during 16:00-18:00 UT on 5 July 2006 (day 12 before the earthquake, increases) and 22:00-24:00 UT on 8 July 2006 (day 9 before the earthquake, decreases), there is little possibility that they are related to the earthquake. Also, when we spatially check the LLT maps during these two periods, we do not find any corresponding anomalies in the preparation zone. Thus, the temporal and spatial coincidences strongly suggest that the TEC anomaly on 15 July is the seismo-ionospheric precursor of the south of Java earthquake.

Meanwhile, the anomalous variations in the measured plasma parameters from DEMETER satellite are observed in the daytime on the same day (15 July 2006, Fig. 7). In comparison with GPS satellites, the DEMETER satellite can only pass through the earthquake preparation zone at two local times: 10:30 and 22:30 LT. Thus, it provides us an opportunity to confirm observed TEC anomalies by GPS satellites in the daytime, although the penetration of anomalous electric field into the ionosphere in the nighttime will be more efficient than that in the daytime (Pulinets and Boyarchhuk, 2004). A dominant increase in electron density by $19.52 \%$, which exceeds the upper bound and reaches the 
maximum value, is observed at about 10:30 LT on day 2 before the earthquake, which is consistent with the TEC enhancements during 09:00-13:00 LT (02:00-06:00 UT). The total ion density also increases to its maximum value within the same period. The main component $\mathrm{O}^{+}$density increases by $13.94 \%$ while $\mathrm{H}^{+}$density simultaneously decreases by $11.72 \%$ and $\mathrm{He}^{+}$density remains relatively stable. However, the decreases in electron and ion temperature are also observed within the same period. It should be noted that almost all of the abovementioned plasma parameters over the earthquake preparation zone on 15 July 2006 simultaneously yield their extremum values, but remain stable during the remaining time, for the whole quiet geomagnetic period from day 45 before to day 10 after the earthquake. The results shown in Fig. 7 indicate that the plasma variations on 15 July are very likely related to the south of Java earthquake.

An anomalous "asymmetric" structure appears in the LTT plots (Fig. 5) within the latitude range of $\sim 10^{\circ} \mathrm{S}-30^{\circ} \mathrm{N}$ during the period of $\sim 02: 00-10: 00 \mathrm{UT}$ (around the earthquake time 08:19UT) on 16 and 17 July 2006. However, located there is a "peanut-pod-like" distribution whose waist line roughly overlaps with the magnetic equator on other days. Moreover, as shown in Fig. 6, the asymmetry coefficients $\alpha_{m}$ at four central symmetric latitude pairs with respect to the magnetic equator increase simultaneously from 15 July and reach their peaks on 17 July 2006 (the earthquake day) and then return to the normal levels gradually. The latitude range of the reduced TEC on the epicenter side in the LTT plots, marked by the two black dashed ellipses in Fig. 5, are exactly located over the earthquake preparation zone. Although the perturbation process is not fully understood in great detail, the reductions in the GPS TEC might be caused by the change of the electromagnetic environment (i.e., radiations, low-frequency electric fields and magnetic fields, etc.) around the forthcoming epicenter area during the earthquake preparation period (Freund, 2000; Bhattacharya et al., 2009; Liu et al., 2009). On the one hand, the seismo-generated radiations might cause the plasma thermal expansions and result in a large volume of the ionospheric electron density reduction and outflow into the magnetosphere along the Earth's magnetic field line (Liu et al., 2009). On the other hand, the disturbed electric field would also be able to produce a plasma $\boldsymbol{E} \times \boldsymbol{B}$ drift (westward or eastward), which in turn results in the extreme reductions in the GIM TEC (Liu et al., 2009, 2010, 2011). Despite all that, this subject also needs to be further investigated in the future.

In conclusion, the temporal and spatial anomalies of the GIM TEC and striking plasma variations from the DEMETER over the epicenter indicate the existence of a significant preseismic ionospheric precursor on day 2 before the earthquake. In particular, the localization and synchronization of the long time anomalies around the occurrence of earthquake suggest that these perturbations on 15 July 2006 are highly related to the south of Java earthquake. However, the pertur- bation process is still not fully understood in great detail and needs further investigation in the future.

Data availability. GPS data are available from https://cdaweb.gsfc. nasa.gov/sp_phys/. DEMETER data are accessible from https:// cdpp-archive.cnes.fr. All earthquake data are available from https: //earthquake.usgs.gov/earthquakes.

Competing interests. The authors declare that they have no conflict of interest.

Acknowledgements. We acknowledge use of GPS TEC data provided by the Center for Orbit Determination in Europe (CODE) and DEMETER data available from the CDPP server (https:// sipad-cdpp.cnes.fr/). We also thank the National Earthquake Information Center (NEIC) ComCat database of the US Geological Survey for providing available earthquake data. This work was supported by National Natural Science Foundation of China (grant number 41431071).

The topical editor, E. Roussos, thanks two anonymous referees for help in evaluating this paper.

\section{References}

Akhoondzadeh, M., Parrot, M., and Saradjian, M. R.: Electron and ion density variations before strong earthquakes $(M>6.0)$ using DEMETER and GPS data, Nat. Hazards Earth Syst. Sci., 10, 718, doi:10.5194/nhess-10-7-2010, 2010.

Berthelier, J. J., Godefroy, M., Leblanc, F., Seran, E., Peschard, D., Gilbert, P., and Artru, J.: IAP, the thermal plasma analyzer on DEMETER, Planet. Space Sci., 54, 487-501, doi:10.1016/j.pss.2005.10.018, 2006.

Bhattacharya S., Sarkar, S., Gwal, A. K., and Parrot, M.: Electric and magnetic field perturbations recorded by DEMETER satellite before seismic events of the 17th July 2006 M7.7 earthquake in Indonesia, J. Asian Earth Sci., 34, 634-644, doi:10.1016/j.jseaes.2008.08.010, 2009.

Dobrovolsky, I. R., Zubkov, S. I., and Myachkin, V. I.: Estimation of the size of earthquake preparation zones, Pure Appl. Geophys., 117, 1025-1044, doi:10.1007/BF00876083, 1979.

Freund, F.: Time-resolved study of charge generation and propagation in igneous rocks, J. Geophys. Res., 105, 11001-11019, doi:10.1029/1999JB900423, 2000.

Ho, Y. Y., Jhuang, H. K., Su, Y. C., and Liu, J. Y.: Seismoionospheric anomalies in total electron content of the GIM and electron density of DEMETER before the 27 February 2010 M8.8 Chile earthquake, Adv. Space Res., 51, 2309-2315, doi:10.1016/j.asr.2013.02.006, 2013.

Jhuang, H. K., Ho, Y. Y., Kakinami, Y., Liu, J. Y., Oyama, K. I., Parrot, M., Hattori, K., Nishihash, M., and Zhang, D.: Seismoionospheric anomalies of the GPS-TEC appear before the 12 May 2008 magnitude 8.0 Wenchuan Earthquake, Int. J. Remote Sens., 31, 3579-3587, doi:10.1080/01431161003727796, 2010. 
Kakinami, Y., Liu, J. Y., Tsai, L. C., and Oyama, K.I.: Ionospheric electron content anomalies detected by a FORMOSAT-3/COSMIC empirical model before and after the Wenchuan Earthquake, Int. J. Remote Sens., 31, 3571-3578, doi:10.1080/01431161003727788, 2010.

Karia, S., Sarkar, S., and Pathak, K.: Analysis of GPS-based TEC and electron density by the DEMETER satellite before the Sumatra earthquake on 30 September 2009, Int. J. Remote Sens., 33, 5119-5134, doi:10.1080/01431161.2012.657375, 2012.

Lebreton, J. P., Stverak, S., Travnicek, P., Maksimovic, M., Klinge, D., Merikallio, S., Lagoutte, D., Poirier, B., Blelly, P. L., Kozacek, Z., and Salaquarda, M.: The ISL Langmuir Probe experiment and its data processing onboard DEMETER: scientific objectives, description and first results, Planet. Space Sci., 54, 472486, doi:10.1016/j.pss.2005.10.017, 2006.

Liu, J., Zhang, X., Novikov, V., and Shen X.: Variations of ionospheric plasma at different altitudes before the 2005 Sumatra Indonesia Ms7.2 earthquake, J. Geophys. Res.-Space, 21, 91799187, doi:10.1002/2016JA022758, 2016.

Liu, J. Y., Chen, Y. I., Chuo, Y. J., and Tsai, H. F.: Variations of ionospheric total electron content during the Chi-Chi Earthquake, Geophys. Res. Lett., 28, 1383-1386, doi:10.1029/2000GL012511, 2001.

Liu, J. Y., Chuo, Y. J., Shan, S. J., Tsai, Y. B., Chen, Y. I., Pulinets, S. A., and Yu, S. B.: Pre-earthquake ionospheric anomalies registered by continuous GPS TEC measurements, Ann. Geophys., 22, 1585-1593, doi:10.5194/angeo-22-1585-2004, 2004.

Liu, J. Y., Chen, Y. I., Chen, C. H., Liu, C. Y., Chen, C. Y., Nishihashi, M., Li, J. Z., Xia, Y. Q., Oyama, K. I., Hattori, K., and Lin, C. H.: Seismoionospheric GPS total electron content anomalies observed before the 12 May 2008 Mw7.9 Wenchuan earthquake, J. Geophys. Res., 114, A04320, doi:10.1029/2008JA013698, 2009.

Liu, J. Y., Chen, Y. I., Chen, C. H., and Hattori, K.: Temporal and spatial precursors in the ionospheric global positioning system (GPS) total electron content observed before the 26 December 2004 M9.3 Sumatra-Andaman Earthquake, J. Geophys. Res., 115, A09312, doi:10.1029/2010JA015313, 2010.

Liu, J. Y., Le, H., Chen, Y. I., Chen, C. H., Liu, L., Wan, W., Su, Y. Z., Sun, Y. Y., Lin, C. H., and Chen, M. Q.: Observations and simulations of seismoionospheric GPS total electron content anomalies before the 12 January 2010 M7 Haiti earthquake, J. Geophys. Res., 116, A04302, doi:10.1029/2010JA015704, 2011.

Liu, J. Y., Chen, Y. I., Huang, C. C., Parrot, M., Shen, X. H., Pulinets, S. A., Yang, Q. S., and Ho, Y. Y.: A spatial analysis on seismo-ionospheric anomalies observed by DEMETER during the 2008 M8.0 wenchuan earthquake, J. Asian Earth Sci., 114, 414-419, doi:10.1016/j.jseaes.2015.06.012, 2015.

Parrot, M., Benoist, D., Berthelier, J. J., Błęcki, J., Chapuis, Y., Colin, F., Elie, F., Fergeau, P., Lagoutte, D., Lefeuvre, F., Legendre, C., Lévêque, M., Pinçon, J. L., Poirier, B., Seran, H. C., and Zamora, P.: The magnetic field experiment IMSC and its data processing onboard DEMETER: scientific objectives, description and first results, Planet. Space Sci., 54, 441-455, doi:10.1016/j.pss.2005.10.015, 2006.
Pulinets, S. and Davidenko, D.: Ionospheric precursors of earthquakes and global electric circuit, Adv. Space Res., 53, 709-723, doi:10.1016/j.asr.2013.12.035, 2014.

Pulinets, S. A. and Boyarchuk, K. A.: Ionospheric Precursors of Earthquakes, Springer Science \& Business Media, Berlin, 2004.

Pulinets, S. A., Legen'Ka, A. D., Gaivoronskaya, T. V., and Depuev, V. K.: Main phenomeno-logical features of ionospheric precursors of strong earthquakes, J. Atmos. Sol.-Terr. Phy., 65, 13371347, doi:10.1016/j.jastp.2003.07.011, 2003.

Pulinets, S. A., Ouzounov, D. P., Karelin, A. V., and Davidenko, D. V.: Physical bases of the generation of short-term earthquake precursors: a complex model of ionization-induced geophysical processes in the lithosphere-atmosphere-ionospheremagnetosphere system, Geomagn. Aeronomy, 55, 521-538, doi:10.1134/S0016793215040131, 2015.

Schaer, S.: Mapping and predicting the Earth's ionosphere using the Global Positioning System, Geod.-Geophys. Arb. Schweiz, 59, 1999.

Yan, X. X., Shan, X. J., Cao, J. B., Tang, J., and Wang, F. F.: Seismoionospheric anomalies observed before Wenchuan earthquake using GPS and DEMETER data, Seismol. Geol., 34, 160-171, 2012.

Yan, X. X., Shan, X. J., Cao, J. B., and Tang, J.: Statistical analysis of electron density anomalies before global M-w $>=7.0$ earthquakes (2005-2009) using data of DEMETER satellite, Chinese J. Geophys.-Ch., 57, 364-376, doi:10.6038/cjg20140203, 2014.

Zhang, X., Shen, X., Liu, J., Ouyang, X., Qian, J., and Zhao, S.: Analysis of ionospheric plasma perturbations before Wenchuan earthquake, Nat. Hazards Earth Syst. Sci., 9, 1259-1266, doi:10.5194/nhess-9-1259-2009, 2009a.

Zhang, X. M., Shen, X. H., Ouyang, X. Y., Cai, J. A., Huang, J. P., Liu, J., and Zhao, S. F.: Ionosphere VLF electric field anomalies before Wenchuan $M 8$ earthquake, Chinese Journal of Radio Science, 24, 1024-1032, 2009b.

Zhao, B., Wang, M., Yu, T., Wan, W. X., Lei, J. H., Liu, L. B., and Ning, B. Q.: Is an unusual large enhancement of ionospheric electron density linked with the 2008 great Wenchuan earthquake?, J. Geophys. Res.-Atmos., 113, A11304, doi:10.1029/2008JA013613, 2008.

Zhima, Z., Shen, X. H., Zhang, X. M., Cao, J. B., Huang, J. P., Ouyang, X. Y., Liu, J., and Lu, B. Q.: Possible ionospheric electromagnetic perturbations induced by the Ms7.1 Yushu earthquake, Earth Moon Planets, 108, 231-241, doi:10.1007/s11038012-9393-z, 2012a.

Zhima, Z., Shen, X. H., and Cao, J. B.: Statistical analysis of ELF/VLF magnetic field disturbances before major earthquakes, Chinese J. Geophys.-Ch., 55, 3699-3708, doi:10.6038/j.issn.0001-5733.2012.11.017, 2012b. 